\title{
WestVirginiaUniversity
}

THE RESEARCH REPOSITORY @ WVU

Graduate Theses, Dissertations, and Problem Reports

2008

\section{Online communities' impact on the profession of newspaper design}

Amanda Miller

West Virginia University

Follow this and additional works at: https://researchrepository.wvu.edu/etd

\section{Recommended Citation}

Miller, Amanda, "Online communities' impact on the profession of newspaper design" (2008). Graduate Theses, Dissertations, and Problem Reports. 1912.

https://researchrepository.wvu.edu/etd/1912

This Thesis is protected by copyright and/or related rights. It has been brought to you by the The Research Repository @ WVU with permission from the rights-holder(s). You are free to use this Thesis in any way that is permitted by the copyright and related rights legislation that applies to your use. For other uses you must obtain permission from the rights-holder(s) directly, unless additional rights are indicated by a Creative Commons license in the record and/ or on the work itself. This Thesis has been accepted for inclusion in WVU Graduate Theses, Dissertations, and Problem Reports collection by an authorized administrator of The Research Repository @ WVU. For more information, please contact researchrepository@mail.wvu.edu. 


\title{
ONLINE COMMUNITIES' IMPACT ON THE PROFESSION OF NEWSPAPER DESIGN
}

\author{
Amanda Miller \\ Thesis submitted to the \\ Perley Isaac Reed School of Journalism \\ at West Virginia University \\ in partial fulfillment of the requirements \\ for the degree of \\ Master of Science \\ in \\ Journalism
}

\author{
Steve Urbanski, Ph.D. \\ George Esper, Ph.D. \\ Jaci Webb-Dempsey, Ph.D. \\ Rick Bebout, M.S.J. \\ Journalism Department \\ Morgantown, West Virginia \\ 2008
}

Keywords: Online Community, Newspaper Design, Professional Virtual Community, Community of Practice 


\begin{abstract}
Online Communities' Impact on the Profession of Newspaper Design

Amanda Miller

The importance of the Internet to visual journalists is increasing with every technological progression. Recently online communities have formed, creating a commonplace for creative professionals to meet and share visual work. This study focuses on the possible impact of these emerging online communities on the newspaper design profession. Interviews of newspaper designers who participate in online communities specifically focused on the profession unveiled current and important transformations occurring within the newspaper design profession. Additionally, this study expands on both offline and online community theory, giving qualitative insight into future studies which may focus on the Internet's effects on various professions.
\end{abstract}


Online Communities' Impact on the Profession of Newspaper Design

Table of Contents

Chapter I: Introduction, Problem, Purpose, Research Question, \& Methodology ............................

Chapter II: $\quad$ Literature Review ......................... 11

Chapter III: A general history of newspaper design with the purpose of describing how the Internet and online communities have naturally entered the profession of newspaper

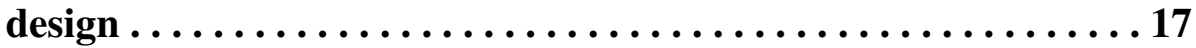

Chapter IV. Description of the theoretical notion of community and whether there is a difference between online and traditional

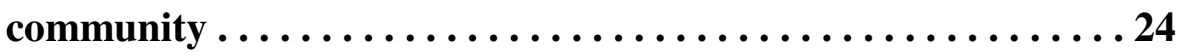

Chapter V. Theory Constructing Reality: Actual stories showing the impact of online community on the newspaper designer's professional life supported by theory ................ 29

Chapter VI. Analysis of the Data \& Conclusion $\ldots \ldots \ldots \ldots \ldots \ldots \ldots \ldots \ldots$

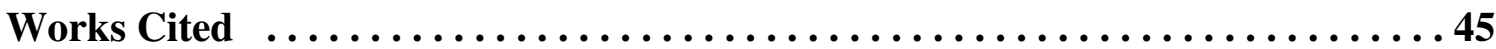

Appendices

Appendix A. Email Interview Protocol . . . . . . . . . . . . . 49

Appendix B. Other Newspaper Design Web sites Mentioned for Use by Participants . . . . . . . . . . . . . . . . 50 


\section{Introduction}

Within recent years, online communities, otherwise known as "Internet-groups and collectives" (Wilson and Peterson 2002), have become common connectors of all Internet users who share similar interests in a subject (Lindlof and Schatzer 1998). Social online community Web sites such as Facebook and MySpace have become extremely well-known and widely used in social circles today by helping to create a virtual network of friends. Following the technology-savvy trend, professional communities, such as newspaper designers, have also turned the Internet into a global network for communicating with colleagues and those who share similar professional interests.

Newspagedesigner.com (est. 2002) is known in newspaper design circles as one of the first of these sites and has facilitated employment connections with its main attraction - portfolio postings. Professionals in the news design field come to this site to recruit potential hirers, have their work discovered, and to find and share design tips and ideas.

Visualeditors.com (est. 2004) is another well-known site within this niche of those interested in news design which facilitates open-forum discussions and job postings among professionals and beginners alike. Visualeditors.com's creator, Robb Montgomery, defines the Web site as "a non-profit group and online community dedicated to journalism education, (VisualEditors.ning.com).” In an interview Montgomery said that Visualeditors.com began as a strictly forum-based Web site. The one time page one editor for the Chicago Sun-Times started Visualeditors.com in his downtime in the daily newsroom. "Forums gave a meeting place to people like myself," Montgomery stated. Once blogs and portfolio posting evolved, Montgomery said he had 
his Web site "jump to the next wave of technology," (Miller, Montgomery Interview, July 2008). And jump it has. The Web site boasts phenomenal growth since its beginnings in March 2004, and as of July 2008 serves over 5,000 registered, active members and a frequently returning audience that is even larger (Visualeditors.com). The Web site states that, "In April 2007: Visualeditors.com saw 60,218 Unique Visitors, 154,363 total visitors and 1,873,023 page views a month," (Visualeditors.org/theaudience, July 2008).

During the progression of this research (February 2008), Montgomery launched a more socially adept version of the VisualEditors.com Web site using the URL Visualeditors.ning.com through the use of another Web site, Ning.com (est. 2004), (Miller, Montgomery Interview, July 2008). Ning.com offers one standard "programmable platform" for creating social networks online and boasts that it "powers the largest number of social networks on the Internet," (Ning.com, March 2008). Similar to the format of social networking sites such as Facebook.com and MySpace.com, this updated version allows community members to create personal profiles, write their own blogs, start and join online discussions, share videos and photos, create groups, and invite others who share an interest in newspaper design to join their online community. Montgomery's reasoning for using Ning.com was he "had no time for the meltdowns" that were happening with his own software on his original Web site and stated that Ning.com is also better at fighting "spam and worm attacks". As of July 2008, Visualeditors.ning.com had over 1,300 members (Miller, Montgomery Interview, 2008). While both the original site and the ning.com site were active and in use as of July 2008, 
the effects of the addition of VisualEditors.ning.com on VisualEditors.com's users were not examined within this research.

\section{Statement of the Problem and Justification}

With the advent and growth of professional Web sites such as Newspagedesigner.com and Visualeditors.com, newspaper design has become a more publicly prevalent profession today than it has ever been. Thanks to these sites and a few others, a tight-knit niche community of designers and visual journalists is forming. These sites provide access to those who were once perceived as professionally and/or geographically inaccessible. Expert, moderate, and novice newspaper designers now possess the ability to better educate the uninformed on the visual side of the news business. This said the emerging importance of these sites in the everyday life of the newspaper designer has created a need for further research surrounding the development of newspaper design as a career since online communities have evolved.

\section{Purpose of the Study}

The purpose of this exploratory research is to shed light on a topic which has yet to be examined within published academic research: online community's impact on the newspaper design professional. By focusing this research primarily on the impact of the developing online community formed as a result of Web sites specifically pertaining to newspaper design, such as Newspagedesigner.com and Visualeditors.com, I hope to unveil the most current and important issues and changes occurring in the newspaper design profession which are a result of the Internet's ability to create a useful online community. Additionally, this study will try to expand on the existing body of online 
community theory, specifically that which focuses on the Internet's effects on various professions.

I have observed within my preliminary research that The Virginian-Pilot, a reputable daily newspaper within newspaper design circles based out of Norfolk, Virginia, recently (2007) downsized their visual department, leaving top designer, Charles Apple to find new work. Also, although currently the school is searching for strong multimedia and visual faculty members, as an undergraduate and graduate student at West Virginia University's (WVU) P.I. Reed School of Journalism for the past six years, I have observed a lack of available and thorough visual journalism education here.

It seems that visual journalism is on the verge of change, but whether the positive changes outweigh the negative has yet to be determined. The news design profession is an aspect of visual journalism that has only been truly developing to the point where it is now since the advent of the Macintosh computer and the emergent use of color in the 1980's (Shepard 1996). The goal of my research is to provide an opportunity for newspaper design professionals, as well as all visual journalists, to get an idea of which direction the profession is headed. Furthermore, the grounded theory derived from my research should provide both the academic and professional journalism community, alike, motive to conduct further research on the subject of newspaper design by highlighting that the visual journalism field continues to grow and develop as a result of the development of technology. 


\section{Research Question}

How is the available online community of newspaper designers impacting newspaper design professionals?

\section{Methodology}

Throughout my research I used snowball sampling to gather interview participants. This method was particularly useful in gaining access and trust within the community of newspaper designers with the use of referencing a friend or colleague's name.

I also gained access to the community of newspaper designers through immersing myself in the newspaper design online community. I began my preliminary research by introducing my study and eliciting participation with a post on Visualeditors.com's "Education" discussion forum on 10/16/2007 entitled: "How have Web sites impacted your newspaper design experience?" The body of the posting read:

Hi All!

I am currently gathering research for my thesis on how open online forums and portfolio postings have changed the newspaper design profession within the last few years. I would like to open discussion on how careers, educational experiences, or any other parts of your life- big or small- have been impacted by visualeditors.com and newspagedesigner.com.

Please do not hold back. Since newspaper design has barely made a splash within the vast sea of research, I am looking for any and all input to create a project which will compile as much input as possible into one substantial piece that will provide important information for academics and professionals alike.

For those of you who have especially felt an impact from these websites and have lots more to share than what you feel can be expressed thoroughly over this forum, I would love to interview you over the phone or possibly in person.

You can email me at acmills22@yahoo.com. 
By presenting the open-ended question which asked how online community had personally impacted each respondent's newspaper design experience, the opportunity was presented for a variety of replies. As of 1/30/2008, my posting had been viewed 1,527 times. At the same date, only five individuals had replied by posting responses in the forum and one email was sent to me directly by an individual who had not posted responses in the forum. There were a total of six individual respondents, all of which were currently working professionals in the field of newspaper design at the time.

Charles Apple, graphics designer for The Virginian-Pilot and an avid blogger for Visualeditors.com, was chosen for an in-person, in-depth interview using a snowball sampling approach from the post's respondents. I also spoke to Robb Montgomery, newspaper and digital journalism consultant and founder and CEO of Visualeditors.com, by telephone interview. I initially sought Montgomery's interview because of his response to my Visualeditors.com post, but his contact information was given to me by Apple, a long-time friend and colleague, who referred to each other as "brothers". I then conducted an un-timed, three-hour qualitative in-depth interview with Apple at his office at The Virginian-Pilot in Norfolk, Virginia on 11/20/2007. During this interview, I received much useful information and six additional contacts. From Apple's suggested contacts, I again used snowball sampling to send an email questionnaire to these six people, all of which were either currently working in newspaper design, or have had significant experience in the profession during the impact of newspaper design online communities. I also sent the questionnaire to two contacts given to me by my research chair, Steve Urbanski, former designer for the Pittsburgh Post-Gazette. 
My decision to send an email questionnaire was made with the intention that respondents would have a chance to better think about their responses to questions, as opposed to an in-person or over-the-phone interview. Using eight open-ended questions, I allowed for respondents to bring to attention topics that may not have been already discussed by Apple, as well as to back-up some issues that he had already expressed, without chance of leading or biasing any of the discussion towards any specific themes that I could possibly bring up. Also, respondents to the question in my preliminary research, "How have Web sites impacted your newspaper design experience?" posted all positive opinions in their entries on Visualeditors.com. I believe this may have been a result of the respondents' fear of the side-effects of saying anything negative about the Web site while using it, as well as a fear of a backlash from the community of newspaper designers, colleagues, and friends. Because this email questionnaire was not affiliated with any Web sites, I hoped that it would help to relieve any possible pressure on respondents to answer only positive aspects about these Web sites. Along with requested demographic information, questions in the email questionnaire were asked directly as follows:

1. Please list any Web sites you use which you consider to specifically pertain to newspaper design(ers) and how often you use them.

2. Describe your original motives for using these Web sites.

3. Please explain the ways in which you participate, or have participated, with any Web sites which primarily focus on newspaper design.

4. Describe any positive aspects you have witnessed from using these Web sites which focus on newspaper design. (Personal or otherwise)

5. Describe any negative aspects you have come across from using these Web sites which focus on newspaper design. (Personal or otherwise) 
6. How do you think Web sites specifically focused on newspaper design have changed the field, if at all?

7. What do you see for the future of the field as a result of Web sites specifically focused on newspaper design?

8. Thank you so much for your participation in this project! Please add any additional information or anecdotes that you think may help to increase my understanding of the impact of the developing online community of newspaper designers.

The opportunity for follow-up questions was also granted by each respondent.

I eventually noticed an ongoing pattern within my email elicitation, the time constraints of each individual newspaper designer seemed to be very similar. I contacted eight newspaper designers asking for their help with the email questionnaire. Five responded enthusiastically to helping with the research, but in the end, two out of these five enthusiastic respondents actually returned the completed the questionnaire. The exceptions to this trend were Julie Elman, current assistant professor at Ohio University's School of Visual Communication, who responded within twelve hours of receiving the questionnaire; and Josh Crutchmer, Deputy Presentation Editor at the Omaha WorldHerald, and one of two contributors to Sportsdesigner.com. Crutchmer replied after two reminder emails sent over the course of four weeks. Both Elman and Crutchmer responded with extremely thorough and well-thought out answers to the questions.

Hoping to expand on my results by varying my interview methods, I decided to conduct a 30-minute, over-the-phone interview using these eight questions as guidelines. Urbanski then suggested an interview with friend and colleague, Diane Juravich, current Features Design Director for the Pittsburgh Post-Gazette.

The in-person interview with Apple and phone interviews with Juravich and Montgomery allowed me the ability to immediately expand on answers given by the 
participant during the interviews. Apple's interview differed from Juravich's and Montgomery's, in that since Apple's was the first of my exploratory interviews, I had not yet developed a set of questions to ask participants. The answers that Apple provided allowed me to develop an idea of what I would be looking for in further interviews, and I developed my set of questions from here.

One difficulty this created for Juravich's and Montgomery's interviews was that I now had to avoid asking questions which would indefinitely lead me to answers which I began to expect from repeating patterns in the data thus far, i.e. Apple's interview, two email questionnaire responses, and the six Visualeditors.com posting responses. In the end, my sample consisted of five interview participants (two phone, one in-person, two by email) and six separate respondents to an elicited question on Visualeditors.com, totaling eleven participants for the study's sample. Most respondents were working currently as newspaper designers, with the exception of one interviewee who was recently retired from newspaper design after fifteen years in daily news and looking to teach at the college level, and another interviewee who was also recently retired and currently teaching at a visual communications college. The years of professional newspaper design experience within this group ranged from four to more than fifteen.

\section{Theoretical Approach}

Philosopher Richard Rorty, stated in "Contingency, Irony, and Solidarity” (1989),

"The world does not speak. Only we do. The world can, once we have programmed ourselves with a language, cause us to hold beliefs. But it cannot propose a language for us to speak. Only other human beings can do that," (Rorty, 6, 1989). Rorty further elaborates on this statement by saying that humanity's use of language games is neither 
arbitrary nor is it the "expression of something deep within us," (Rorty, 6, 1989). This study should run parallel to Rorty's theories in that it will extend on the idea that it is not the Internet that has changed communication and human language, but instead Internet communication has allowed humans to change the use of language over Web discussion, and therefore how certain Web sites are used by humans.

The use of computer-mediated communication (CMC) to form a community of newspaper designers is the main focus of this study. Following the hermeneutical approach of social theorist Hans-Georg Gadamer from his seminal work "Truth and Method" (1975), I will explore the use of Web sites specifically pertaining to newspaper design by newspaper design professionals as an interpretational text. Thus meaning I will be looking at Web sites as a body of text from which I can extract important data on the use and behavioral trends of various online participants. In order to build significant grounded theory, and to further triangulate this study, information gained within these interviews will be used in a Gestalt-like manner. This means I will be conducting interviews in which certain issues pertaining to the impact of CMC on newspaper designers will arise. Data collected through interviews will be placed into a theoretical background within this thesis so as to maintain focus on the current trends in newspaper design as a profession as opposed to leading focus to the common issues which arise in the data. Also, at times these issues will be presented in the foreground to further accentuate and illustrate their significance to existing online community theory. 


\section{Chapter II. Literature Review}

Published academic research on the development of newspaper design as a profession as a direct result of the introduction of online community specifically for those interested in newspaper design does not yet exist.

There have, however, been a growing number of published studies on the developing profession of newspaper design and design trends. These studies can be traced by the development of technological advances leading up to the use of the Internet and the development of online communities (Utt \& Pasternack 1993, Geraci 1995, Russial 1995, Bennett \& Hightower 1991, Shepard 1996; Zavoina \& Reichert 2000).

Trend studies over the past three decades have outlined changing appearances of newspapers, use of new technologies and software to assist designers, and the dynamics of newsroom staffing and the changes made as a result of the design profession gaining more attention (Utt \& Pasternack 2003).

Many designers believe that the informational graphics boom of the 1980s was a direct result of the introduction of USA TODAY in 1982 (Shepard 1996). USA TODAY did not invent informational graphics (i.e. charts, maps, tables, diagrams which explain worded information visually) but together with the invention of the Macintosh Computer (Mac) in 1984, designers were able to edit graphics directly from outside sources instead of editing them by hand. The Mac computer has also made drastic changes in the development of pagination, i.e. the laying out of news pages using the computer (Shepard 1996).

Also during the time of the introduction of USA TODAY (mid 1970s), came the emergence of color trends in newspapers (Shepard 1996). A series of studies during the 
1980s, 1990s, and again in 2003 by Utt and Pasternack revealed a drastic increase in color photo usage between 1982 and 1987. In 1982, 30.3 percent of respondents indicated they never used color photos, while in 1987 only 13 percent could say the same. The 2003 study showed that $93.9 \%$ of papers run all of their photos in color.

It is believed by some in the newspaper industry that "factors that ultimately shape decision making and goals in newsrooms ultimately shape content itself (Lowrey 2002)." Published articles and studies outlining the importance of the evolving power of the visual journalist in the newsroom have added relevant supporting evidence to this claim in recent years (Gentry \& Zang 1989; Lowrey 2002, 2003; Moses 2003).

During the 1980s and into the 1990s, the great divide in the newsroom between "word" people and "visual" people was becoming prevalent (Lowrey 2002). While research on the topic was developing on the role of the visual journalist, the newest title in the newsroom was forming, the graphics manager (Gentry and Zang 1989, Geraci 1984). In 1989, Gentry and Zang called for further research on the attitudes of visual editors versus word editors towards each other and the perception of each others' roles in the newsroom after their study on the role of the graphics manager discovered a working divide between visual and word people in the newsroom. This study describes the graphic manager's responsibility as the "person who oversees the visual presentation of the news, including photography, illustration, information graphics, typography, page design, and use of color." It was the graphic manager's job to "ensure that visual information communicates rather than decorates" (Gentry and Zang 1989). Visual titles in the newsroom which have evolved as a result of the convergence of online and print news are 
Visual Editor, Visual Journalist, and Web Director depending on "which skills are used to manage visuals" (Zavoina and Reichert 2000).

Recent studies have been developed around the social norms that are facilitating the divide between visual and word journalists. In a 2002 case study of newsrooms, William Lowrey theorized that social norms were conflicting in the newsroom, causing a distinct separation of subgroups of designers, reporters, and photographers. Lowrey stated that as a result, a tendency for visual journalists to avoid conflict with other subgroups at work has developed, resulting in a lack of important debate over "the way news should be visually framed for audiences."

In 2003, the results of a national survey of newspaper organizations by Utt and Pasternack said that larger newspapers (measured by total circulation) produced better professionally judged design quality. The determined cause of these results was a more abundant level of design resources and higher degree of "specialized" expertise within the staff of larger newsrooms (Utt and Pasternack 2003).

Studies have shown that recent changing trends in technology have provided opportunity for persons with a variety of experiential backgrounds to become designers in the newsroom. In 2003, Utt and Pasternack conducted a questionnaire aimed at 857 daily newspapers' staff members who were "primarily responsible and/or most knowledgeable of the layout and design of both the print and the online editions." The study concluded that front-page design is "no longer the sole domain of journalism graduates" or of those with a strong "news background" and that an art or computer science graduate is also capable of designing front pages as long as the newspaper uses a template. Lowrey found that 75 percent of design directors participating in his survey stated that all or most of 
their design staffs have had some sort of formal art educational background (Lowrey 2002).

Lowrey and others' research on the background education of the design community was conducted during the same time that the Newspagedesigner.com (2002) and Visualeditors.com (2004) Web sites were launched. As a result of the developing online community of visual journalists and newspaper designers, further research is needed regarding the effects of free dissemination of information over online facilities (specifically Newspagedesigner.com and Visualeditors.com) on whether those who are currently employed as designers have used online communities to gain their positions and/or enhance educational development.

The body of empirical research on online communities is vast. There are many varying types of online communities which are said to usually be formed by persons who share a common interest or a shared characteristic (McQuail 149).

In a uses and gratifications study which outlined types of Fantasy Sports users and their motivations for use of this specific competitive online community, researchers found that not all online communities "build or maintain relationships" (Farquhar \& Meeds 2007). A 2002 study was conducted to "articulate how the term 'community' has been used to identify, describe, and construct online contexts and groups" (Brown 2002). From this study, Nicole Brown of Purdue University theorized that homogenous groups of users in online communities facilitate a "stark divide/boundary between those on the inside and those on the outside" (Brown 2002). Both Newspagedesigner.com and Visualeditors.com are available to all who choose to look at the Web sites. By applying Brown's theories it would be beneficial to find out who is using these sites in order to 
decide whether a divide in the newspaper community between visual versus word, or "those on the inside" versus "those on the outside," is being facilitated by use of these specific sites. A homogenous group of primary visual site users could show a divide being perpetuated by these sites while a mostly heterogeneous group of visual and word site users would provide further insight into the use of online community as a means of narrowing the gap of understanding each other's professional roles in the newsroom.

Social networking or otherwise known as Web 2.0 sites, such as Facebook and MySpace, have been the subject of much literature concerning the usage of online communities within the college student community (Skiba 2007, Spencer 2007). As a result, these sites have enabled informational exposure about this specific niche to those outside of the college community. For example, news reporters are said to be using these Web sites to give news stories "at the very least" color, details, and depth through personal perspective (Spencer 2007). Web sites which allow individuals to post their design work such as Newspagedesigner.com are available to give both those on the inside and outside of the news design profession an idea of the changing trends in the field.

In a 2007 interview Tim Frank, creator of Newspagedesigner.com, revealed that visual journalists are becoming "more marketable because of the exposure" of their work on the Web site through their portfolio postings and "some have even achieved a level of celebrity" (SND Update Blog 2007). In 2007 Lampel and Bhalla theorized that a community, both online or offline, that "uses prestige to attract participation is also likely to reinforce status-seeking behavior by its members." This suggests that the image of these websites, i.e. whether they are seen as exclusive or as "open, democratic forums," should be able to be reflected when exploring how prestige effects both visual and word 
persons' attractions to using the News Page Designer and Visual Editors sites. Also, since Lampel and Bhalla's theory states competitive status seeking is "harder to sustain in online communities that have open admission policies" it should be beneficial to explore whether both visual and word users are attracted to these sites' open admission policies. Furthermore, another recent study has found that participation in online communities results in social capital (i.e. trust and reciprocation) online (Kobayashi, et al. 2006). Therefore it can be hypothesized that those who are most trusted within these online communities should be those who participate the most and therefore gain the most "status" within both the online community and offline communities of newspaper design. The effects of these online community theories which carry over into the offline community of the working profession of newspaper design are what is hoped to be discovered through this exploratory research. 


\section{Chapter III. A general history of newspaper design with the purpose of describing how the Internet and online communities have naturally entered the profession of newspaper design}

While examining the changes that have been made in the practice of newspaper design over the years, it is evident that technological advances are a major supporting cause to the profession's growth, both technically and socially. Developments in typesetting, page layout, and design trends have all been shaped by advancements in technology.

During the late 1800 s and into the early 1900s daily newspapers were the only source of news and the first mass medium (Berry, ix). Experimentation with teletype, linotype, stereotype, and photoengraving allowed for creativity to run rampant. Covers during this time resembled the tabloid magazine covers of today, using shocking headlines written with the intent to draw a reader to purchase the publications.

The use of photographs on front pages and loud typefaces borrowed from advertising posters are trends from the early ages of newspaper which are still widely used on today's front pages, but technological advances through computer programs such as QuarkXpress and InDesign have allowed for much more additional experimentation in the area of page layout or "pagination."

Once newspapers began creating influential brand names such as Pulitzer's New York World, profit starting building from outer sources and newspaper covers started keeping a 'straighter' appearance so as not to disturb investors and to maintain a more serious image (Berry, ix). Innovation turned to formula and formula turned to convention as most papers adopted a standard eight-column vertical format. 
"A study of newspaper design during the inter-war years of 1920 to 1940 concluded that design change was neither sudden nor linear and came about only through experimentation at the newspapers (Utt and Pasternack, 2003)." From experimentation of this time came the great early innovators of newspaper design in the 1950s. Edmund Arnold was considered the "Father of Modern Newspaper Design" and helped implement changes that became new standards for the time. He made the shift from eight columns to six for greater legibility, created modular layout (using squares of texts instead of long chutes), and believed in using photographs to enhance a story instead of the obligatory head shots which most newspapers had become accustomed to (Bernstein, Washington Post 2007). Arnold was involved in the redesign of over 600 publications (Shepard 1996). "At a time when no one really cared how newspapers looked, Ed Arnold told them to reorganize and reduce clutter," Mario Garcia, another design icon out of this area once stated about his friend Arnold (Bernstein, Washington Post 2007).

Garcia and Arnold came into the design consultant profession before books and courses on newspaper design existed. Graduating from the University of South Florida and starting out as a news reporter at the Miami News, Garcia found himself enthralled with cutting out sections of newspapers and reconstructing the front pages to his liking. Garcia describes the reason for a lack of educational materials on the subject when he says, "With newspapers in the 1950s, when 90 percent of Americans subscribed, you didn't pay for a paper for its beauty,"(Shepard 1996).

Garcia is considered an extremely valuable resource to newspaper design as he has personally and professionally experienced two major transformations of the design revolution; the emergence of color in the mid-1970s and the advent of informational 
graphics (i.e. chart, maps, tables, diagrams which explain worded information visually) in the 1980s (Shepard 1996).

The emergence of color is a trend phenomenon that is still being studied today. A series of studies from the 1980s, 1990s, and again in 2003 by Utt and Pasternack revealed a drastic increase in color photo usage between 1982 and 1987. In 1982, 30.3 percent of respondents indicated they never used color photos, while in 1987 only 13 percent could say the same. The 2003 study showed that $93.9 \%$ of papers run all of their photos in color.

Many believe that the informational graphics boom of the 1980s was a direct result of the introduction of USA TODAY in 1982. USA TODAY did not invent informational graphics, but together with the invention of the Mac computer in 1984 designers were able to edit graphics directly from outside sources instead of editing by hand (Shepard 1996). The Mac computer has also made drastic changes in the development of pagination — laying out pages on the computer (Shepard 1996).

Distinction between occupational subgroups at a newspaper (i.e. a newsroom's photographers, reporters, designers, and copy editors) has been a result of the development of separate professional organizations, conferences, publications, and distinct curricula in journalism schools (Lowrey 2002). Newspaper designers have been gaining professional recognition outside of the newsroom since the Society of News Design (SND) was formed in 1978 at the first Newspaper Design Seminar at the American Press Institute in Reston, VA (www.snd.org). As of late 2007, SND boasted enrollment of 2,500 members from all over the world and has said to have connected "all 
who have a professional interest in news and newspaper design" with its annual workshops and competitions (www.snd.org).

Although technology is undoubtedly changing the way in which newspaper designers are communicating, some designers are grasping to the traditional mindset of past successors. Edmund Arnold once said, "Good design is simply a package in which we deliver some information. The content must always be more important than the package," (Shepard 1996). Today's newspapers are putting Arnold's words into practice by hiring graphics directors who believe in content-driven design. Apple describes himself as an "information architect” (Miller, Apple Interview 2007). Apple's graphics career began in the beginning of the informational graphics boom in 1982 at the Evening Herald in Rockhill, South Carolina where he says he "witnessed a sleuth of newspapers adding pictures for the pictures sake, or simply because USA TODAY was doing it"common mistake in the newsroom during the birth of informational graphics which he adamantly preaches against in his 2007 SND conference seminar pamphlet.

There was a time when SND conferences and annuals were the only way for most working in the newspaper design industry ideas to learn about what was going on in the field. Today, the Internet has developed new methods for designers to not only learn, but to communicate their own personal theories behind the profession. It has also become a central location to debate these theories. The Internet has also had a part in positive and negative changing perceptions of the profession of newspaper design significantly, both from the outside of the profession and within. One issue that has risen in the profession is because of the ability the Internet has given newspapers to outsource designers in foreign countries for less pay. In January 2008, The Miami Herald had gone public with a 
decision to outsource its editorial design from a company in India, a much debated topic on the Web sites Newsdesigner.com and Visualeditors. $\operatorname{com}^{1}$. The publication soon reneged its decision, as the backlash from designers came pouring in. The reason cited on their Web site went as follows, "The more we looked at the prospects of editing and layout from outside the newsroom, the more it was clear these skills involving news judgment and experience are not likely to work well from afar." ${ }^{2}$ From this statement, one could gather that newspaper designers are gaining value from upper management of their respective publications and places of work, but many continue to fear their jobs will eventually be outsourced. Julie Elman, says she wasn't surprised at The Miami Herald's decision not to outsource, but still worries that editors will eventually "resort to templates to get the job done and save money," (Miller, Elman Interview 2008). Steve Yelvington, a self proclaimed "lifelong journalist" and a strategist for a media company, wrote in his blog that The Miami Herald "erred" because "editorial judgment is a key competitive advantage to having in-house designers, as opposed to outsourcing." ${ }^{3}$ Montgomery posted a response to Yelvington's comments on 01/15/08 about outsourcing newspaper designers stating:

I have met the CEO of this firm on a few different occasions (In Moscow and Boston) and what his company is really good at is handling the advertorial preprinted workload. Assembly work essentially that takes your copy and art and delivers camera-ready or completes the work to finished files using your existing pagination system. I saw some of the work they do for UK pubs and the South China Morning Post - impressive.

It is a huge leap from that type of work to jump into the editorial decision making process that local news presentation demands and that's where Anders drew the line - but the advertorial work seems to be still be on track. If doing that non-

\footnotetext{
1 (http://www.newsdesigner.com/archives/002863.php).

2 (http://www.newsdesigner.com/archives/002869.php).

3 (http://www.yelvington.com/20080115/outsourcing_wrong_stuff).
} 
editorial work at 40 percent of the cost from a remote location saves editorial jobs and expertise in a newsroom - why wouldn't you try for that? ${ }^{2}$

Many designers seem to agree that high quality design for newspapers is important for increased sales. Patrick O'Brien posts on Yelvington's blog, “Newspapers continue to look dull and unattractive across the country. A well-designed product that looks compelling will sell better than a well-written product that looks garish.” Not everyone agrees. Jay Small, "respected leader and longtime executive in the interactive media industry" (as stated by his Web site ${ }^{4}$ ) replied to O'Brien's post by disagreeing with the notion that good newspaper design is a good investment for all newspapers. Small writes, "Papers may look dull to designers, but to everyday readers, the most important considerations remain:

1. Can I read it easily?

2. Can I tell what is being conveyed as most important?

3 . Is the content interesting/relevant/provocative to me?"

In Small's opinion, format is important, but states, "If the content is dull, good design doesn't help." He also refers to good design as "false advertising," that is if it represents dull content.

Expression of opposing views on the importance of newspaper design is a common factor on design Web sites and blogs. This particular exchange of text shows that no matter what the outcome, some designers welcome the challenge to defend their profession, at least online. Whether this kind of open-debate is a commonality of offline interaction in the newsroom, for example, is something that further studies should explore

\footnotetext{
${ }^{4}$ Smallinitiatives.com/about-small-initiatives
} 
in order to uncover whether designers are actually impacted by Internet depersonalization theories.

By opening the door for open-communication, technology has taken the news design profession this far and is undoubtedly a force behind these changing trends. Further trends in newspaper design and changes in the way others perceive newspaper design should be expected to approach the masses must faster in the near future, as a result. In order to keep up, those interested in the news design field must track future changes in the way the world is using technology and how it is further linking communication around the world. 


\section{Chapter IV. Description of the theoretical notion of community and whether there is a difference between online and traditional community}

During my research, certain members of this offline newspaper design

professional community, who are also members of the online community of newspaper designers, acted as representatives of the profession by describing their experiences in online communities through interviews and questionnaires. Participants conveyed statements that reflected the identity of both the online and offline community of newspaper designers, thus showing the Internet impacts both the online and offline (traditional) lives of newspaper designers. However, further explanation of the similarities and differences of online and offline communities need to be afforded within this research in order to evaluate the data properly.

The term "online community" has been theorized to have many meanings providing not one single definition (Wise, Hamman, \& Thorson 2006). Conflicting definitions may have been a result of many conflicting uses of online communities. In the past few years, literature has been evolving rapidly regarding the trends in usage and motivations of certain niche online communities (Kobayashi et al. 2006; Youcheng Wang \& Fesenmaier 2004; Knapp, et al. 2007; Farquhar \& Meeds 2007; Skiba 2007; Spencer 2007).

Rheingold's (1994) definition of "virtual communities" states that one "can be formed by any number of individuals by way of the Internet at their own choice or in response to some stimulus (McQuail 2005, 149). For the purpose of maintaining consistency within the duration of this paper, the term "online community" will refer to Lindlof and Schatzer's (1998) definition of "virtual community" as one "founded intentionally by people who share a set of similar interests, often revolving around certain 
texts or tropes imported from non-CMC (computer-mediated communication) venues, such as soap operas and their characters." My research examines Web sites, as opposed to e-mail or other methods of online communication, specifically ones in which their participants have imported their non-CMC text on the subject of newspaper design to the individual Web site.

The term "community," referring to the traditional definition of the word and without regard to communication over the Internet, has been defined very similarly to an online community, as a group of interacting people sharing "similar understandings, values, life practices, histories, and identities within a certain framework of variation,"(Hyland 2005, 53). Additionally, a singular community is said to have its own sense of identity, of which it is "capable of acting on its behalf or on the behalf of those who have a claim on that identity (Hyland 2005, 54).

The concept of identity is not lost on the online community of newspaper designers. The definitions of "identity" in both offline and online situations are basically the same, i.e. "a complex personal and social construct, consisting in part of who we think ourselves to be, how we wish others to perceive us, and how they actually perceive us," (Wood and Smith 2005, 56). The difference between representation of identity online versus offline is that the mediation of technology creates an easier way to alter our self presentation, or the identity in which we want others to perceive us, online (Wood and Smith 2005, 56).

This community of newspaper designers, both online and traditional (offline), can be identified with Van Maanen and Barley's (1984) definition of a “work community," a.k.a. that in which "a group of people who consider themselves to be engaged in the 
same type of productive work activity, whose identities are shaped by their work, and who share a set of work-related practices, norms and values, and meanings that influence not only their work but their social lives as well," (Hyland 2005, 134).

When focusing specifically on the Web, the online community of newspaper designers could also be defined as a professional virtual community (PVC). A PVC's objective is said "to encourage people to exploit or explore knowledge through Web sites," (Chen 2007). Two separate types of virtual communities have been theorized by Wenger (1999), 'communities of practice' is one, and the other type is 'communities of purpose' (Cummings, et al. (2006). According to Wenger, work-related online communities are considered communities of practice. Web sites pertaining to newspaper designers are considered a place where those in the field can come to communicate, share, and expand their knowledge on the profession, therefore creating a work-related online community. Therefore, newspaper designers have developed a community of practice by communicating with others on these professionally-centered Web sites.

The difference between communication offline and online is that online communication is mediated by technology. In academic research, online communication is often referred to as computer-mediated communication (CMC). CMC research focuses on studying how behaviors are "maintained or altered by exchange of information through machines," as opposed to immediate interaction, by use of "intentional human communication," (Wood \& Smith 2005, 4). Following the guidelines of CMC research, data obtained from participating newspaper designers in this study should offer an insider's view into the professional life of a newspaper designer during an age of developing online community, displaying how the participants believe their behaviors, 
and the behavior of other members of the online community of newspaper designers to which they belong, are impacted offline by certain Web sites.

One effect of CMC on its users is said to be a possible increase on dependence of technology. Multiphrenia, is a term used by Kenneth Gergen (1991) which argues that machines have given people an overwhelming choice of self expression, and as a result we increasingly turn to a more (computer and governmentally) mediated society (Wood \& Smith 2005, 6). It is a norm in today's workplace that any project represents a positive form of self-expression, as well as a test of skill-level, and therefore, must be mediated by some form of technology, whether a Microsoft Word document, PowerPoint slides, etc., in order to appear finished. The newspaper designer's job is one in which the worker depends on the mediation of technology to express the final product of their work, through both pagination and graphical design. The logical question to ask next is how the turn of a solely offline community of newspaper designers into the development of an online community of newspaper designers relates to/was a result of this newly developed opportunity for self expression?

Another factor that may be leading professionals to depending on a computermediated society is that " $\mathrm{CMC}$ interaction questions the assumption that a community is geographically bound" and that its members must inter-act face-to-face (Wood and Smith 2005, 123). Because these Web sites have opened the doors to what was once geographically-limited communication, it is inevitable that the involved community become increasingly dependent on it to communicate with those they would not otherwise be in contact without the technology. Within an online work community this may mean an increase in the use of certain Web sites to make professional connections 
and to find employment. Because newspapers' designers are no longer geographically bound, a community in which one's identity as a professional is able to be critiqued by a number of professional peers has developed. The fact that a newspaper designer's portfolio of work can be shown globally by a mediator, i.e. the Internet, may be the result of an overly mediated society, but is also proven to be an extraordinarily positive factor for the development of the profession. 


\section{Chapter V. Theory Constructing Reality: Actual stories showing the impact of online community on the newspaper designer's professional life supported by theory}

It has been said that, "the effects of the Internet might be easier to ignore if they only affected the worlds that exist online," (Wood and Smith 2005, 145). During this chapter, data received within this study which has shown the impact of the Internet on both the offline and online worlds of newspaper designers will be analyzed.

Ishii and Ogasahara (2007) conducted one of few studies on the link between "real and virtual networks," comparing two different types of online communities; those which they say are "mostly rooted in real-group personal relationships," and those which are not but instead develop from "members' individual interests." Since newspaper designers, as well as many other professionally niched groups are becoming active on Web sites which specifically pertain to their profession, it's possible that these individuals join on behalf of both "real-group personal relationships," for example, if a designer visited a Web site because of a recommendation to the site by a co-worker, and also as a result of their own "individual interests." A newspaper designer's intent to join the online community of designers could be based on either real or virtual networks. In regards to this study's data, the Internet has affected all members of the online community of newspaper designers through both a professional's real and virtual networks.

Ishii and Ogasahara's (2007) study concludes that the "effects of the Internet are culture-specific and that the online community can serve a different function in different cultural environments." This thesis presents evidence to suggest that individual professional communities, such as the one being examined, are in themselves culture- 
specific, thus upholding that the effects of the Internet upon individual communities of a certain practice must be further studied in order to conclude the Internet's culturally specific impact on varying communities of practice. Chen (2007) highlights a need for further research on individual PVC's by stating, "What motivates individuals to participate in virtual communities of practice may be different for intra-organizational and inter-organizational virtual communities of practice." Chen's study on the "factors influencing members' continuance intentions in professional virtual communities," also calls for opinions of those who were once involved in certain online communities and who have since ceased to participate (Chen 2007). This study's interview sample includes such members, as well as members of the online community of newspaper designers with varying activity levels.

A community of practice is said to have positive aspects for its members including providing a place for innovation to occur, for new practices to be formulated, and for social learning to take place (Cummings, et al. 2006). In the beginning of newspaper design online community, pioneer portfolio posting Web site, Newspagedesigner.com emerged as the place where newspaper designers converged to share portfolios and look over other designers' work. Visualeditors.com became the place for forum discussion on newspaper design. Soon after, newspaper designers' experiences with other designers began to expand and their perceptions of the identity of their own profession began to evolve.

One common, yet not guaranteed, side effect of forum discussion and CMC is said to be depersonalization. Wood and Smith further comment that although "sufficient evidence exists that CMC is not inherently depersonalizing, it can effect one's judgment 
sometimes causing "flaming," or the sending of messages which are "intended and/or interpreted to be hostile in nature," (Wood and Smith 2005, 91). According to Philip Thompsen (1996) and by use of the social influence model of technology use (Fulk, Steinfield, Schmitz, \& Power 1987), the act of "flaming" can be the result of familiarity with the social conventions of technology (Wood and Smith 2005, 93). Crutchmer stated, "these sites are often blogs or message boards, and the opportunity for discussions to take ugly turns, involving personal attacks, immaturity or petty bickering is always out there." One positive side effect that I had found in my data was that this feeling of depersonalization can lead to a series of, at times hostile, but at other times very constructive debate that may not be as successful face-to-face because of intimidation factors. Elman describes her experience with facing opposing views over online design postings:

Once upon a time, when Newspagedesigner.com was all the rage, I would comment on many pages I saw being posted. I, along with my colleagues at The Virginian-Pilot (Norfolk, Va.), made it a point to defend the art and craft of visual journalism whenever we read the rantings of a NPD poster who called himself "Wordhawk." This guy thought designers were idiots and illiterate. We tried to be as relentless in responding as he was in posting his prolific musings. We used to call "it" (NPD? Workhawk bashing?) "crack" because we simply couldn't help ourselves. We couldn't resist getting on NPD and joining in whatever design brawl was happening at the time, even though we knew that we weren't engaging in dialogue - we were just feeding some guy's ego and urge to be the bad guy. But it sure was fun and entertaining while it lasted (Elman, questionnaire response, 2008).

Elman's experience exemplifies how easy it is to form groups through the Internet

medium based on ideas and opinions. In fact she states that she no longer posts threads on

Visualeditors.com. She expanded on this thought by saying,

It was an inclusive site, and everyone was welcome. That was my sense. Reading the different threads, though, was sometimes difficult because I noted that sometimes there might be two or three or four of the same people bantering back and forth. Honestly, I think that's normal for any site like this. 
Elman stated the four reasons for her motivation to join in on newspaper designoriented Web sites as: "community, education, curiosity, and inspiration for future designs." What resulted from posting her work on Newspagedesigner.com (that she hadn't expected) was a greater exposure of her work and a startling increase in reputation both internationally and among her colleagues. Elman describes her experience:

Before I posted anything on Newspagedesigner.com, I was an anonymous designer, like everyone else. No big deal -- I was used to this. Shortly after I started posting pages to NPD, I started to hear from designers from across the U.S. and around the world (Russia and Canada, for example). People also left comments on my posted pages, and some folks actually sent me e-mails to ask me to critique their pages, give them advice about design, or to just tell me that my work inspired them to take visual risks. My name showed up on sites like Visualeditors.com when people mentioned designers whose worked they admired.

I was amazed by the attention that my pages received. I am my own worst critic, and I just couldn't understand what they were all seeing in my pages (and to be fair, many of my pages, like all front pages, are very much collaborative efforts of many on the newsroom staff). All this validation came to me at a time when I was feeling not so confident about my work, so hearing everyone's nice comments was both affirming ("I must be doing something right") and confusing ("Oh my God, I'm a fraud and wait until everyone finds out").

When I showed up to my first SND annual workshop, I was treated like a 'design goddess' (which is what some people called me - NOT that I encouraged that). I was flattered and felt very uncomfortable at the same time. I almost had a heart attack when Denise Reagan (active in SND, acted as moderator/host during the banquet in San Jose) asked me to participate in a little fun Q\&A session, off the cuff - in front of about 850 people. I said 'thanks, but no thanks.' I'm convinced none of this would have happened if newspagedesigner.com hadn't come on the scene (Elman, questionnaire response, 2008).

Others have reiterated Elman's thoughts and experiences by describing newspaper design Web sites as a place to find "who's doing what," stating that opposed to before these Web sites started "there was now a name attached to a page" and that "Newspagedesigner.com helped generate a culture of celebrity within the design world."

Some participating members of the newspaper design online community have had similar experiences with an increase in professional reputation resulting from posting 
work online and have embraced the opportunities that have resulted. Montgomery stated that when the daily newspaper he worked for laid him off in 2001 he had "no contacts outside of his Rolodex and a short email contact list," (Miller, Montgomery Interview, July 2008). In contrast, Montgomery states that today these newspaper design Web sites should allow anyone who has been suddenly laid off to "feel empowered to find a way out" by the leverage that the hundreds to thousands of contacts that these Web sites can potentially give a good designer to get hired. He also added that recent layoffs "have nothing to do with the job performance of journalists. Many journalists think that being laid off is a stain on their record when it isn't, they are usually completely competent." Jim McBee, managing editor for SmartNews and frequent forum discussion contributor to Visualeditors.com explains the effect that these Web sites have had on a newspaper's ability to hire talented designers:

I was an early adopter of Visualeditors.com Somehow, my e-mail address was on Robb Montgomery's initial spam announcing vizeds' launch and I jumped right in. Posting there and having a portfolio on Newspagedesigner.com led directly to a job offer at Bluffton Today, a startup in Bluffton, S.C. A vizeds-friendly designer at the Savannah Morning News who I didn't even know pointed out my portfolio to the person who was developing the prototype. I know I'm not the only person who's gotten a job directly through vizeds. I have recruited designers that I met or noticed through visualeditors, and I'm sure I'll do that again (Jim McBee, Visualeditors.com Forum Post, email response, October 2007).

The ability Visualeditors.com's online posting gives for showcasing work also helped an aspiring designer, Josh Bohling from the University of Texas, Arlington, a small school with not much of a reputation for design get hired. His design posting, which he outwardly named his "homage to Julie Elman's work" on the Web site, quickly gained Elman and staff for The Virginian-Pilot's attention, as well as landed him his first design job out of college (Miller, Apple Interview 2007, Miller, Elman Interview 2008). 
As easy as it is for some to give credit to creators of great work posted online, it is just as easy for others to take credit away from those who rightfully earned it. "Because the information on the sites is so immediate, people are less inclined to strictly rip off somebody else's work, but it certainly enables people if they're thinking along those lines," Diane Juravich stated in an interview. It would seem to some that as opposed to a primarily social online network, these professional Web sites would usually attract those who would not want to falsely represent themselves, for fear of a backlash from the professional community which would negatively affect the future of their own career. But because very few legal restrictions can be placed on those wishing to create a greater public perception of themselves through posting work on Web sites, there have been some instances where members of the online community of newspaper designers, much like a real-life community, must act as a "watch dog" to prevent abuse of the growing amount of design resources online and the development of copycats.

Elman acknowledges that she has observed problems involving copycats of others' online design work postings. In her experience, Elman said that when instances of plagiarism (or near-plagiarism) occurred, "the newspaper community seemed to call people out" and "big discussions all over the design Web sites" resulted (Miller, Elman Interview 2008). Even so, Crutchmer feels that there has been an even more negative impact on the design world's creativity as a result of copycats:

Walk through the judging tables at the annual SND competition now, and you'll see a lot of similar pages, a lot of similar concepts, centerpieces and approaches (whether that's in a photo, typography, color, structure or overall design). There are many people who won't share their work online now because they feel they've been "ripped off" or worse as a result. As a result of all of this, it can be very difficult for a designer to feel like he or she has done something completely original now (Josh Crutchmer, questionnaire response, 2008). 
This ability for open-communication has offered the online newspaper design community more than the ability for crime monitoring. Participation on Web sites which particularly focus on newspaper design also offers open communication to a profession which formerly existed on strict space and time restraints. From the data, one of the main perceived benefits of this new ability to openly communicate was the opportunity for access outside your own personal newsroom and into others'. This is made especially available through forum discussion and portfolio postings.

The news design Web sites have made it possible for artists/designers to actually reach beyond the black hole of their newsrooms and form a community. It used to be you had to wait for a conference or the SND annual to have any clue what was going on in the outside world (Stacy Innerst, Visualeditors Post, October 2007).

Between VisualEditors.com and the annual SND Workshop in San Jose, California, I went from knowing no one in the business to knowing everyone in the space of about a year (Jim McBee, email response to Visualeditors Post, 2008).

Another perceived benefit was the ability to obtain further education in newspaper design once out of college or in addition to the classroom. Josh Crutchmer, one of two contributors to Sportsdesigner.com, explains his opinions on the educational aspect of these sites:

The opportunity to learn and improve has increased exponentially with these sites. Whether that's the ability to reach out to others in the industry through these sites or to learn specifically from a post or article written on these sites, I'd say it cut my career learning curve at least in half if not more to be a part of all these sites (Josh Crutchmer, questionnaire response, 2008).

Through interviews and through what I personally observed over the Web sites, I found that idea sharing through these Web sites can encourage feedback. The ability to leave feedback was highly regarded by many participants, who believe ultimately it will encourage better quality design. Molly Parsons believes that receiving feedback, whether online or offline is "one of the best ways to grow and learn as a designer." Parsons 
followed this by stating, "I have found that seeing others' work and seeing how good some of the good out there really is challenges you to make your stuff that much better."

Although designers value the ability to learn from others online, many were also concerned about the amount of work being posted on these Web sites. Some have noticed a lack of editing which they believe can lead to "quality" design getting lost in the clutter. Here are a few elaborative statements on the subject:

People seem to post everything they do and I think that you really need to post your best pages (Diane Juravich, telephone interview, 2008).

It makes it challenging for me to explain to students what quality means when such a huge range of examples show up 'published' (Julie Elman, questionnaire response, 2008).

Many designers place value in the increase in prospective hires these Web sites give to potential employers as a result of portfolio postings. For example, the work of potential designers at small schools and rural areas that may have been overlooked in the past because of time constraints and other various reasons are now more easily accessible through Web site postings. "I have my own site, but a central gathering place for newspaper designers' portfolios is invaluable for people who do the hirings," John Zhu stated, (Visualeditors.com Post, October 2007). This was said to lead to a higher level of skill now needed for hiring designers at newspapers. "What's great about this for hiring is that you constantly have candidates. You're not just waiting for someone to walk in the door. You're researching student work. Seeing who are the hot designers coming out of school and then you can look at their work online. You can pursue them immediately," Diane Juravich stated in a telephone interview.

Some respondents showed signs of negative feelings about the personal impact of increased exposure of designers by these Web sites, even when the exposure is positive. 
One anonymous designer represented showed evidence of those with now perceived higher design skills, experiencing higher performance pressure in the newsroom with this statement:

One editor I worked with would sometimes push me to create a page that would 'beat' certain other papers... I was pissed. Oh my God. We spent so much time talking about 'the reader' at newspapers, and suddenly I've got this editor breathing down my neck (Anonymous Response).

I also observed the impact of these Web sites' perceived positive effects creating high expectations for all newspaper design by designers, themselves. Elman stated that she is "surprised at the number of U.S. newspapers out there that look as bland and boring as can be given the number of good, visual resources online." During the research this seemed to be the general feeling of many experienced newspaper designers, which leads myself, as the researcher, to believe that better attention to the training and education of both future news designers and also potential employers of news designers. 


\section{Chapter VI. Analysis of the Data \& Conclusion \\ Looking to the Future of Newspaper Design Online Communities}

An interesting observation from this research has been that the interaction on some newspaper design Web sites tended to mirror situations in everyday communities

outside of the Internet. The question that needs to be answered now is: What will make these Web sites continue to be successful in creating online community that is perceived as beneficial to newspaper designers?

Through Montgomery's experience with Visualeditors.com, he has come to believe that it takes "healthy communication and activity with over 1,000 participants" This is at least what he says helped to "establish the Visualeditors name in the public's minds."

Montgomery goes on to mention "peer-to-peer critiques" and job advice as two valuable mainstays in his site's available activities. Blogging on certain Web sites was seen as a very valuable educational asset for many designers in this study. But just like any professional conference or meeting, it seemed important to these newspaper designers that the blogs on these sites be kept relevant and up-to-date in order to keep the interest of participants.

As stated previously, the discussion forums on Visualeditors.com were described by one respondent as "cliquish" and another who described their experience with this Web site stated that they did not participate in the "blogging" but would instead use the site to "breeze through" when told about an interesting post by colleagues. Participating newspaper designers often stated they had heard about certain Web sites from editors and trusted colleagues. The respondent who did not participate on the Web sites as much as 
the others, seemed to be negatively affected by seeing the same names of the same people posting information in the forums. This person said they used the sites mostly to "keep up with colleagues." Elman stated she visits certain Web sites pertaining to newspaper design, but her usage usually depends upon her teaching curriculum. Once a frequent user of Web sites such as Visualeditors.com, Elman said that, “At some point, I just drifted away," (Miller, Elman Interview 2008).

As a result of this research, I believe if the contributors to these Web sites must do more than simply keep the blogs relevant. More creative, interactive methods must be used in order to make those who want to be involved in these Web sites, feel a part of the culture of these online communities. When asked how Visualeditors.com has kept a returning audience Montgomery made this observation:

(Visualeditors.com) has always pretty much been an experiment with the goal being, 'YOU'RE writing the homepage, not me."' Montgomery also added that, "Newspapers are traditionally not training focused. This worked well when they were the monopoly (for continuing education). Now more people have control (by communicating online), and now this is no longer the way to manage a (daily newspaper) staff.

Following this ideal, Montgomery kept students interested in visual journalism, as well as Visualeditors by holding the first Visualeditors offline training camp in Chicago, Illinois, in May 2008 entitled “Camp Video Journalism.” Sharing experiences is a major aspect of building a community, both online and in-person. As a result of the camp, Montgomery stated participants requested for him to create a Web site where they could keep in touch and talk about shared experiences, which he created soon after and named Campvj.com.

Another example of methods for continuing interest in the Web site would be keeping users active in the site, for example, Charles Apple's continuing contributions. 
Although Apple no longer works at The Virginian-Pilot, he remains active on the Visualeditors.com Web site as a blogger.

The data suggests that many designers may turn away from the use of professional Web sites when they feel they are not a part of group activities such as discussion forums and portfolio postings. I believe that if participants were able to interact better on the Internet, they would in turn invest some personal relevance to the sites, which should contribute positively to future of the Web site a whole, such as team building exercises might offer in offline professional situations. If there is no interactive participation available, the sites run the risk of excluding many potential great newspaper designers from continuing to value these Web sites as a successful communication tool. In a worst case scenario, experienced newspaper designers were to stop using these sites, this could create the possibility of bringing back the old ways of communication so many participants of this study spoke against, i.e. being only informed about the "good designers" and what was going on in newspaper design through annual magazines and conferences. The most important thing for these sites to do at this time, for the profession of newspaper design as a whole that is, is to keep the experienced designers involved and interested in these Web sites. In order to do this, clutter must be kept to a minimum and misinformation must be able to be removed or corrected by the site owners or participants so that site users do not feel like they are wasting any time while sifting through design cyberspace. 


\section{Looking to the Future of the Newspaper Design Profession}

This excerpt from an email interview sums up the whole of what many newspaper

designers I interviewed hope for the future of their profession:

"Well, I think we're at the point where we've seen and done almost everything that can be done on a two-dimensional broadsheet or tabloid piece of newsprint. These sites have certainly helped foster a culture of sameness in the industry, but that's not necessarily a bad thing, because it has helped those who are setting the standards and raising the bar in the industry stand out for their journalism and not simply their designs. The people who we look up to now as designers, we look up to for what they do with content - how they inform, how they invite readers, how they make the most relevant content accessible. Whereas, 5-10 years ago, we looked up to a lot of the torch-bearers for what they did TO content. It wasn't "decoration" in a negative sense, but certainly there was more of a "wow factor" when you'd see something that just simply looked cool. Now the things that wow you always go beyond that.

That's not to say the best designers five years ago weren't great with content, because they were. But I'm saying the industry, collectively, was easier to impress then.

I think this trend will continue indefinitely. I think in 10 years, the best in our industry will be defined by who does "everything they need and nothing they don't" with every inch of space on a page. I think the SND book and accolades will all become shrines to restraint, cleanliness and structure, as it brings out and enhances content (Josh Crutchmer, questionnaire response, 2008).

\section{Conclusion}

The intent of this study's data was to represent the whole of newspaper designers who participate in online community in this field. I have found that one of the most difficult parts of qualitative research is to stop yourself from developing your own assumptions throughout the analysis process. For example, one designer expressed to me a few days after the interview that they wanted some of their negative opinions about a particular site to be expressed in a positive light. This raised ethical complications in keeping my data accurate while wanting to please the participant, especially since this person plans to read my thesis. This was stressful, but I believe (and hope) I managed to represent this person's thoughts accurately, keeping some of the negative aspects of their 
thoughts, while making sure to clear her name of any possible negative backlash from colleagues.

One aspect of the profession that the research has suggested is that newspaper designers are generally friendly people. Most of those contacted expressed an immediate desire to help with this project.

I also found that newspaper designers are a very busy group. It was much more difficult than I had originally thought to get a few to set a few minutes aside to talk to me, or to even take time to fill out the questionnaire. The questionnaire, in my opinion, was a feasible length but it still might have deterred some respondents. My first email asked for permission to send it, the next was the actual questionnaire. I believe that some may have been intimidated by the open-ended questions or maybe the length and never got around to filling it out.

A larger, broader, and more diverse sample size including college students and those working as newspaper designers in the United States would have been ideal of course, but the time and resources that would have been required to complete this were lacking. More participants who don't use the sites as often, or at all would have also been added to the sample, however, it was difficult to find many who do not use the sites, especially since I am not a newspaper designer. Juravich, who was contacted through my thesis chair, was a designer who did not frequent these Web sites very often, and I believe her opinions were extremely helpful to the sample.

The themes which the data picked up should represent a lot of the impact of these online communities, but of course could not possibly cover every aspect. I am also unsure 
if there was enough triangulation of the data. My interviews were only examined by myself and the themes which arose were from my opinion only.

Concerning future studies, I believe this research has shown the great possibility for many more studies to be conducted using the examination of professional Web sites to expose future trends of varying professions. There was one parallel in the data, however, which stood out as a sign for much needed further research in the field of newspaper design. This dealt with the long-standing careers (15 years each) and recent retirement from the daily newspaper grind of both Charles Apple and Julie Elman. Elman, as stated before, is now a current professor of visual journalism, and Apple has said in an interview that he hopes to follow the same career path in upcoming years. Although these were the only two exposing this trend out of my small sample size, change is inevitable in any profession and I believe it can be safely assumed that these two are surely not the only newspaper designers retiring after long careers and looking to higher education to showcase their vast experience and wealth of knowledge. The question that remains from this fact is how are these Web sites facilitating higher education's use of them for further education in the classroom? During the research, these sites were revered by participants as one of the most useful educational tools in newspaper design. Elman, however, expressed a concern that she has a limited amount of time to visit these sites, as a professor. As educators of future visual journalists, is it enough for these sites to only be mentioned by professors such as Elman in class, or is there further potential for these Web sites to be used by these teachers to further education? 
Montgomery shared that his Web site, Visualeditors.com has "always been student-focused," which he believes attracts teachers to the site. When asked about offering more teaching resources for teachers who use Visualeditors.com Montgomery responded, "I have thought about adding curriculum and lesson plans to (Visualeditors.com), but I wouldn't ask others to (contribute their work) for free." Montgomery stated that if he did offer teaching tools, he would pay others to write lesson plans on his Web site (Miller, Montgomery Interview 2008). This would offer compensation as well as a way to monitor the information being posted as valuable on the Web site.

The fact is all educators are valuable resources to both these Web sites and the public. This being said, it would do both these sites and the public well to cater to teachers, whether this includes ideas for lesson plans, lectures, or even a special section for teachers to exchange their own ideas. Also, if educators put the same amount of time and effort as it took to complete this research into familiarizing themselves with these Web sites, the online community of newspaper designers that already exists should continue to grow and prosper with the additional input of students and future designers. Regarding the use of the Internet for education, the possibilities are endless, in my opinion. It will take further studies to understand how to utilize this medium to the best of its educational ability. 


\section{Works Cited}

Barlow, Aaron. Blogging America: the New Public Sphere. Praeger Publishers: Westport, CT, 2008.

Bennett, D., \& Hightower, P. (1991, Spring). Computerizing Visual Journalism: Lessons from the Writing Labs. Journalism Educator, 46(1), 46-49. Retrieved February 6, 2008, from Communication \& Mass Media Complete database.

Berry, John D. (Foreword by Roger Black). Contemporary Newspaper Design: Shaping the news in the digital age: typography and image on modern newsprint. Mark Batty Publisher: West New York, NJ, 2004.

Brown, N. (2002, June). Community Metaphors Online: A Critical and Rhetorical Study Concerning Online Groups. Business Communication Quarterly, 65(2), 92-100. Retrieved February 6, 2008, from Business Source Premier database.

Chen, I. (2007). The factors influencing members' continuance intentions in professional virtual communities - a longitudinal study. Journal of Information Science, 33(4), 451-467. Retrieved April 7, 2008, from Academic Search Premier database.

Cummings, S., Heeks, R., \& Huysman, M. (2006, November). Knowledge and learning in online networks in development: a social-capital perspective. Development in Practice, 16(6), 570-586. Retrieved March 26, 2008, from Academic Search Premier database.

Farquhar, L., \& Meeds, R. (2007, July). Types of Fantasy Sports Users and Their Motivations. Journal of Computer-Mediated Communication, 12(4), 1208-1228. Retrieved February 6, 2008, from Communication \& Mass Media Complete database.

Gadamer, Hans-Georg. Truth and Method. The Seabury Press: New York, NY, 1975.

Garcia, Mario. Contemporary Newspaper Design: A Structural Approach. Prentice Hall, Inc.: Englewood Cliffs, NJ, 1981.

Gentry, J., \& Zang, B. (1989, Summer/Fall1989). Characteristics of Graphics Managers at Metropolitan Dailies. Newspaper Research Journal, 10(4), 85-95. Retrieved February 6, 2008, from Communication \& Mass Media Complete database.

Geraci, P. (1984, Winter). Comparison of Graphic Design and Illustration Use In Three Washington D.C., Newspapers. Newspaper Research Journal, 5(2), 29-39. Retrieved February 6, 2008, from Communication \& Mass Media Complete database. 
Heller, Steven and Pomeroy, Karen. Design Literacy: Understanding Graphic Design.

Hyland, Stanley E, editor. Community Building in the Twenty-First Century. School of American Research Press: Sante Fe, NM, 2005.

Knapp, S., Polaszek, A., \& Watson, M. (2007, March 15). Spreading the word. Nature, 446(7133), 261-262. Retrieved February 17, 2008, from Academic Search Premier database.

Kobayashi, T., Ikeda, K., \& Miyata, K. (2006, October). Social capital online: Collective use of the Internet and reciprocity as lubricants of democracy. Information, Communication \& Society, 9(5), 582-611. Retrieved February 6, 2008, from Academic Search Premier database.

Lampel, J., \& Bhalla, A. (2007, January). The Role of Status Seeking in Online Communities: Giving the Gift of Experience. Journal of Computer-Mediated Communication, 12(2), 100-121. Retrieved February 6, 2008, from Communication \& Mass Media Complete database.

Latham, Robert \& Sassen, Saskia. Digital Formations: IT and New Architectures in the Global Realm. Princeton University Press: Princeton, NJ, 2005.

Lindlof, T., \& Shatzer, M. (1998, Spring). Media ethnography in virtual space: Strategies, limits, and possibilities. Journal of Broadcasting \& Electronic Media, 42(2), 170. Retrieved February 6, 2008, from Communication \& Mass Media Complete database.

Lowrey, W. (2002, Fall). Word People vs. Picture People: Normative Differences and Strategies for Control Over Work Among Newsroom Subgroups. Mass Communication \& Society, 5(4), 411-432. Retrieved February 6, 2008, from Communication \& Mass Media Complete database.

McQuail, Denis. McQuail's Mass Communication Theory. Sage Publications: London, England, 2005.

Miller, Amanda. Education Forum Topic Posting. 10/ 16/ 2007. [http://www.visualeditors.com/forum/viewtopic.php?t=6798] . Interview with Charles Apple. November 20, 2007.

Moses, Monica. (2003, Summer). The Empowered Visual Journalist. (Cover story). Society of News Design, Design Journal \#87. Accessed from Web on 2/17/2008 [https://www.snd.org/resources/pagecontent/Visual_Thinking.pdf].

Mowshowitz, Abbe. Virtual Organization: Toward a Theory of Societal Transformation Stimulated by Information Technology. Quorum Books: Westport, CT, 2002. 
Pasternack, S. \& Utt, S. (1995, Fall). America's front pages: A 10-year update. Newspaper Research Journal, 16(4), 2-12. Retrieved February 6, 2008, from Communication \& Mass Media Complete database.

Rorty, Richard. Contingency, Irony, and Solidarity. New York: Cambridge University Press, 1989.

Russial, J. (1995, Fall). Pagination and digital imaging. Newspaper Research Journal, 16(4), 42-56. Retrieved February 6, 2008, from Communication \& Mass Media Complete database.

Shepard, A. (1996, December). Designer papers. (Cover story). American Journalism Review, 18(10), 30. Retrieved February 6, 2008, from Communication \& Mass Media Complete database.

Skiba, D. (2007, July). Nursing Education 2.0: Poke Me. Where's Your Face in Space?. Nursing Education Perspectives, 28(4), 214-216. Retrieved February 6, 2008, from Academic Search Premier database.

Spencer, J. (2007, October). Found in (My) Space. American Journalism Review, 29(5), 36-39. Retrieved February 6, 2008, from Communication \& Mass Media Complete database.

Testimonials. http://www.visualeditors.org/testimonials. Accessed on Web 11/5/2007.

Utt, S., \& Pasternack, S. (1984, Winter). Front Pages of U.S. Daily Newspapers. Journalism Quarterly, 61(4), 879-884. Retrieved February 6, 2008, from Communication \& Mass Media Complete database.

. (1989, Autumn). How They Look: An Updated Study of American Newspaper Front Pages. Journalism Quarterly, 66(3), 621-627. Retrieved February 6, 2008, from Communication \& Mass Media Complete database.

. (1993, Summer/Fall 1993). Infographics today: Using qualitative devices to display quantitative information. Newspaper Research Journal, 14(3/4), 146-157. Retrieved December 7, 2007, from Communication \& Mass Media Complete database.

(2000, Spring). Update on infographics in American newspapers. Newspaper Research Journal, 21(2), 55. Retrieved February 6, 2008, from Communication \& Mass Media Complete database. 
. (2003, Summer). Front Page Design: Some Trends Continue. Newspaper Research Journal, 24(3), 48-61. Retrieved February 6, 2008, from Academic Search Premier database.

Washer, P. (2002, October 10). Professional networking using computer-mediated communication. British Journal of Nursing (BJN), 11(18), 1215. Retrieved April 7, 2008, from Academic Search Premier database.

Wilson, S., \& Peterson, L. (2002). The Anthropology of Online Communites. Annual Review of Anthropology, 31(1), 449-467. Retrieved February 25, 2008, from Academic Search Premier database.

Wise, K., Hamman, B., \& Thorson, K. (2006, November). Moderation, Response Rate, and Message Interactivity: Features of Online Communities and Their Effects on Intent to Participate. Journal of Computer-Mediated Communication, 12(1), 2441. Retrieved February 6, 2008, from Communication \& Mass Media Complete database.

Wood, Andrew F. \& Smith, Matthew J. Online Communication: Linking Technology, Identity, and Culture. Lawrence Erlbaum Associates, Inc.: Mahwah, NJ, 2005.

Youcheng Wang, N., \& Fesenmaier, D. (2004, February). Modeling Participation in an Online Travel Community. Journal of Travel Research, 42(3), 261-270. Retrieved February 6, 2008, from Academic Search Premier database.

Zavoina, S., \& Reichert, T. (2000). Media Convergence/Management Change: The Evolving Workflow for Visual Journalists. Journal of Media Economics, 13(2), 143-151. Retrieved February 6, 2008, from Business Source Premier database. 


\section{Appendix A. Email Interview Protocol}

Information provided will be used for a Master of Science in Journalism thesis on online community's impact on newspaper designers and potentially for publication, thereafter.

If you wish for your identity to remain anonymous, please type out a statement saying so here:

First Name:

Last Name:

Geographic Location (City, State, Country):

Years of experience in the field of newspaper design:

Current Employer:

Current Employment Title:

1. Please list any Web sites you use which you consider to specifically pertain to newspaper design(ers) and how often you use them.

2. Describe your original motives for using these Web sites.

3. Please explain the ways in which you participate, or have participated, with any Web sites which primarily focus on newspaper design.

4. Describe any positive aspects you have witnessed from using these Web sites which focus on newspaper design. (Personal or otherwise)

5. Describe any negative aspects you have come across from using these Web sites which focus on newspaper design. (Personal or otherwise)

6. How do you think Web sites specifically focused on newspaper design have changed the field, if at all?

7. What do you see for the future of the field as a result of Web sites specifically focused on newspaper design?

Thank you so much for your participation in this project! Please add any additional information or anecdotes that you think may help to increase my understanding of the impact of the developing online community of newspaper designers.

In order to increase the quality of my research, I may need to contact you with follow-up questions after reviewing your responses. Would you be willing to be contacted for additional questions, if need be?

I can be contacted by email at amille16@mix.wvu.edu and acmills22@yahoo.com, as well as by cell phone at 757-575-5177. 


\section{Appendix B. Other Newspaper Design Web sites Mentioned for Use by Participants}

www.newsdesigner.com

www.newseum.org

www.poynter.org

www.snd.org

www.update.snd.org

www.newsu.org

http://bop.nppa.org/2008/ (plus past years pages)

http://www.poyi.org/65/winners\%20copy.html (plus past years pages)

www.sportsdesigner.com 